\title{
META ANALISIS PENGARUH MODEL DISCOVERY LEARNING TERHADAP PENGUASAAN KONSEP DAN PENGETAHUAN PESERTA DIDIK FISIKA SMA
}

\author{
Elvi Suryanti ${ }^{1}$, Asrizal'1), Fatni Mufit ${ }^{1)}$ \\ 1)Program Studi Magister Pendidikan Fisika, FMIPA Universitas Negeri Padang, Padang, Sumatera Barat, Indonesia \\ Corresponding author : Elvi Suryanti \\ E-mail : Elvi.sydb27@gmail.com
}

Diterima 2 Juli 2021, Direvisi 20 Juli 2021, Disetujui 20 Juli 2021

\begin{abstract}
ABSTRAK
Tujuan penelitian ini adalah untuk mengetahui pengaruh Model discovery learning terhadap penguasaan konsep dan pengetahuan fisika SMA. Metode yang digunakan dalam penelitian ini adalah meta-analisis. Teknik analisis data dalam penelitian ini menggunakan perhitungan nilai effect size untuk setiap artikel. Berdasarkan meta analisis yang dilakukan, dapat dinyatakan bahwa hasil penelitian ini yaitu : 1) pengaruh model discovery learning terhadap penguasaan konsep dan pengetahuan fisika SMA ditinjau dari tahun terbit artikel memberikan efek yang Sangat Tinggi terdapat pada tahun 2017,2018, dan 2020 dengan masing-masing rata-rata effect size yaitu 1,6; 1,15; dan 1,62. 2) pengaruh model discovery learning terhadap penguasaan konsep dan pengetahuan fisika SMA ditinjau dari tingkatan kelas memberikan efek Sangat Tinggi terdapat pada kelas XI dengan rata-rata effect size 1,25. 3) pengaruh discovery learning terhadap penguasaan konsep fisika SMA memberikan efek Sangat Tinggi terdapat pada artikel keenam (J6) dengan nilai effect size 2,38. 4) pengaruh discovery learning terhadap pengetahuan fisika SMA memberikan efek Sangat Tinggi terdapat pada artikel kesepuluh (J10) dengan nilai effect size 3,95. Hal ini menunjukkan bahwa terdapat pengaruh model discovery learning terhadap penguasaan konsep dan pengetahuan fisika SMA.
\end{abstract}

Kata kunci: Discovery Learning; Penguasaan Konsep; Pengetahuan.

\begin{abstract}
The purpose of this study was to determine the effect of the discovery learning model on mastery of high school physics concepts and knowledge. The method used in this research is meta-analysis. The data analysis technique in this study uses the calculation of the effect size value for each article. Based on the meta-analysis carried out, it can be stated that the results of this study are: 1) the effect of the discovery learning model on mastery of concepts and knowledge of high school physics in terms of the year the article was published gave a Very High effect in 2017,2018, and 2020 with each the average effect size is 1.6; 1.15; and 1.62. 2) the influence of the discovery learning model on the mastery of concepts and knowledge of high school physics in terms of grade level gives a very high effect in class $\mathrm{XI}$ with an average effect size of 1.25 . 3) the effect of discovery learning on mastery of high school physics concepts gives a Very High effect found in the sixth article (J6) with an effect size value of 2.38. 4) the effect of discovery learning on high school physics knowledge gives a very high effect in the tenth article (J10) with an effect size value of 3.95. This shows that there is an influence of the discovery learning model on the mastery of high school physics concepts and knowledge.
\end{abstract}

Keywords: Discovery Learning; Concept Mastery; Knowledge.

\section{PENDAHULUAN}

Perkembangan zaman yang diikuti oleh perkembangan ilmu pendidikan saat ini menuntut kualitas yang sangat tinggi untuk melaluinya, terutama kualitas ilmu pengetahuan dan teknologi. Perkembangan ilmu pengetahuan dan teknologi (IPTEK) merupakan salah satu fakta yang memperlihatkan kondisi berkembang dan majunya suatu peradaban. Berkembangnya ilmu pengetahuan dan teknologi tersebut, mengharuskan setiap negara untuk meningkatkan kualitas sumber daya manusia. IImu pengetahuan dan teknologi telah menjadi kebutuhan mutlak bahkan telah menjadi salah satu aspek untuk mengetahui kemajuan dari suatu negara. Perkembangan IPTEK menuntut pendidikan agar dapat menciptakan lulusan yang memiliki keterampilan dan pengetahuan yang luas. Pada umumnya, perkembangan ilmu pengetahuan dan teknologi ditunjang oleh ilmu-ilmu dasar di bidang pendidikan sains.

Pendidikan sains atau IImu Pengetahuan Alam (IPA) merupakan salah satu wahana 
untuk membangun sumber daya manusia yang berkualitas dan mampu menguasai ilmu pengetahuan dan teknologi. Secara umum IPA meliputi tiga bidang ilmu dasar yaitu fisika, biologi, dan kimia. Fisika merupakan cabang ilmu pengetahuan alam yang memberikan kontribusi dan pengaruh besar terhadap kemajuan ilmu pengetahuan dan teknologi. Begitu juga dengan produk teknologi yang dihasilkan, pada umumnya didasarkan pada prinsip fisika. Physics is studying the universe, including matter and energy on a small scale such as atoms (microscopic) and large-scale solar systems (macroscopic). Physics lessons related to natural phenomena are obtained through a series of processes known as scientific processes and interactions with nature (Mufit et al., 2020). Fisika mempelajari alam semesta, termasuk materi dan energi dalam skala kecil seperti atom (mikroskopis) dan tata surya skala besar (makroskopik). Pelajaran fisika yang berkaitan dengan fenomena alam diperoleh melalui serangkaian proses yang dikenal dengan proses ilmiah dan interaksi dengan alam. Pentingnya ilmu fisika dalam kehidupan manusia, maka fisika dijadikan salah satu mata pelajaran di sekolah.

IImu fisika sangat penting dalam ilmu pengetahuan sehingga tidak dapat dilepaskan dari dunia pendidikan, sehingga pemerintah menjadikan fisika sebagai mata pelajaran wajib dipelajari disetiap jenjang pendidikan khususnya setingkat SMP dan setingkat SMA. Dalam rangka meningkatkan mutu pendidikan di sekolah, pemerintah telah melakukan berbagai upaya baik dari segi kuantitas maupun dari segi kualitas. Dari segi kuantitas telah diupayakan pengadaan sarana dan prasarana yang menunjang keberhasilan proses pembelajaran fisika, sedangkan dari segi kualitas, pemerintah telah mengadakan penataran bagi para pendidik mata pelajaran fisika, musyawarah guru mata pelajaran (MGMP) untuk peningkatan mutu pendidik serta meningkatkan kualitas pendidikan, diantaranya dengan melakukan penyempurnaan kurikulum menjadi kurikulum 2013 revisi, meningkatkan kesejahteraan pendidik, serta berbagai upaya lain yang telah diupayakan oleh pemerintah. Dengan upaya yang dilakukan pemerintah tersebut diharapkan dapat meningkatkan mutu pendidikan, khususnya mata pelajaran fisika. Sehingga proses belajar mengajar pada mata pelajaran fisika di kelas lebih menarik, selain itu diharapkan juga seorang pendidik dapat menciptakan suasana kelas yang kondusif dan menyenangkan agar peserta didik tertarik dan termotivasi dalam belajar.

Pendidik dan peserta didik merupakan komponen penting dalam upaya meningkatkan mutu pembelajaran fisika. Peran pendidik dalam kegiatan pembelajaran di sekolah relatif tinggi. Peran pendidik tersebut terkait dengan peran peserta didik dalam belajar. Adapun usaha yang telah dilakukan oleh pendidik dalam peningkatan kualitas pembelajaran yaitu merencanakan kegiatan pembelajaran secara sistematis dengan memanfaatkan segala sesuatu guna kepentingan pembelajaran.

Kenyataan di lapangan mata pelajaran fisika masih dianggap sebagai mata pelajaran yang sulit dan kurang diminati. Selain itu, dalam pembelajaran biasanya peserta didik cenderung merasa bosan dan kurang semangat dalam belajar, untuk menimbulkan semangat peserta didik dalam belajar serta membuat belajar tidak membosankan maka perlu dicari model yang tepat agar dapat meningkatkan hasil belajar. Pada proses pembelajaran pendidik harus bisa mendorong pengembangan kompetensi peserta didik. Dalam hal ini, hendaknya pendidik dapat mendorong perolehan pengetahuan baru peserta didik, meningkatkan keterampilan peserta didik, mendapatkan pengalaman belajar peserta didik dan membangun sikap yang memungkinkan peserta didik untuk belajar (Asrizal et al., 2019).

Berdasarkan pernyataan diatas, maka perlu dicari alternatif lain sehingga proses pembelajaran dapat berlangsung aktif dan mampu meningkatkan hasil belajar. Salah satu model yang dapat meningkatkan hasil belajar peserta didik, sesuai dengan hakikat pembelajaran adalah model pembelajaran discovery learning. Discovery Learning adalah metode pengajaran berbasis inkuiri dan dianggap sebagai pendekatan pendidikan berbasis konstruktivis. Model discovery learning ini menitik beratkan pada kemampuan mental dan fisik para anak didik yang akan memperkuat semangat dan konsentrasi mereka dalam melakukan kegiatan pembelajaran (Rosarina et al., 2016).

Penguasaan konsep adalah usaha yang harus dilakukan oleh peserta didik dalam merekam dan mentransfer kembali sejumlah informasi dari suatu materi pelajaran tertentu yang dapat digunakan dalam memecahkan masalah, menganalisa, menginterpretasikan pada suatu kejadian tertentu (Silaban, 2014). Pentingnya seseorang menguasai suatu konsep adalah agar mampu berkomunikasi, mengklasifikasikan ide, gagasan atau peristiwa yang dialaminya dalam kehidupan seharihari(Suranti et al., 2017).

Rendahnya penguasaan konsep peserta didik dapat ditangani dengan melakukan beberapa upaya. Upaya yang dilakukan tidak hanya berfokus pada pendidik dan peserta didik 
saja, tetapi semua aspek yang ada pada proses belajar tersebut, salah satunya adalah penggunaan model discovery learning terhadap penguasaan konsep fisika. Pembelajaran dengan model discovery learning terhadap penguasaan konsep fisika sangat cocok diterapkan untuk pembelajaran fisika. Model discovery learning model discovery learning terhadap penguasaan konsep fisika akan membuat peserta didik lebih aktif dan pembelajaran menjadi lebih bermakna. Hal itu karena model discovery learning berbasis lingkungan menekankan kepada peserta didik untuk membangun pengetahuannya sendiri dengan memberi permasalahan nyata yang akan memberikan pengalaman langsung kepada peserta didik dalam pemecahannya.

Penelitian meta analisis effect size ini merupakan solusi yang tepat untuk peneliti pilih. Adapun alasan peneliti memilih penelitian meta analisis ini karena beberapa alasan, yaitu : 1) melihat kekonsistenan dari hasil penelitian, 2) melihat penelitian yang cakupannya lebih luas, 3) perlu mengkaji mengenai efek size, 4) melihat kesimpulan penelitian yang lebih luas.

Berdasarkan masalah yang telah dipaparkan, maka peneliti tertarik untuk melakukan penelitian dengan menggunakan metode analisis. Oleh karena itu, judul penelitian ini adalah "Meta Analisis Pengaruh Model Discovery Learning terhadap Penguasaan Konsep dan Hasil Belajar Fisika peserta didik SMA". Dengan demikian, tujuan penelitian ini adalah untuk mengetahui pengaruh Model Discovery Learning terhadap Penguasaan Konsep dan Pengetahuan Fisika SMA.

Berdasarkan latar belakang yang telah dipaparkan diatas, maka masalah yang dikaji dalam penelitian ini adalah sebagai berikut "Apakah terdapat pengaruh model discovery learning terhadap penguasaan konsep dan pengetahuan fisika SMA?.

\section{METODE PENELITIAN}

Jenis penelitian yang diterapkan pada penelitian ini adalah meta analisis effect size dengan mereview 17 artikel pada jurnal nasional dan jurnal internasional. Artikel-artikel yang dianalisis yaitu dari tahun 2015-2021. Analisis yang dimaksud adalah analisis kuantitatif data yang cukup banyak, serta menerapkan metode statistik dengan mempraktekkannya dalam mengorganisasikan sejumlah informasi yang berasal dari sampel besar yang fungsinya untuk melengkapi maksud-maksud lainnya. Data pada penelitian ini menggunakan data sekunder yang dipilih dari beberapa hasil penelitian yang dilakukan sebelumnya.
Instrumen yang digunakan pada penelitian ini dilakukan dengan lembar pemberian kode (coding category). Pengkodean (coding) pada meta analisis merupakan syarat penting agar pengumpulan dan analisis data menjadi mudah. Tujuannya adalah agar variabel-variabel yang dipakai untuk pemberian kode dapat memberikan informasi yang dibutuhkan.

Teknik pengumpulan data adalah teknik dokumentasi terhadap komponenkomponen pada beberapa artikel yang akan diteliti. Artikel yang didapat berkaitan dengan penggunaan model pembelajaran terhadap penguasaan konsep fisika peserta didik serta menyeleksi artikel yang telah didapat melalui google scholar. Dalam meta analisis diperlukan prosedur tabulasi data dalam penelitian. Adapun prosedur tabulasinya dapat dilihat sebagai berikut: 1) mengidentifikasi variabelvariabel penelitian dan memasukannya kedalam kolom variabel yang sesuai, 2) mengidentifikasi nilai rata-rata dan standar deviasi dari kelas kontrol dan eksperimen, 3) jika standar deviasi tidak diketahui, maka langkah selanjutnya adalah menganalisis nilai t pada masing-masing artikel dan 4) melakukan analisis data untuk menentukan nilai ukuran effect size dengan menggunakan persamaan Glass (Glass, 1981). Persamaanya adalah :

$$
\mathrm{ES}=\frac{\underline{x}_{\text {post }}-\underline{x}_{\text {pre }}}{S D_{\text {pre }}} .
$$

Keterangan :

ES : Effect Size

$\underline{x}_{\text {pre }} \quad$ : Nilai rata-rata pretest

$\underline{x}_{\text {post }} \quad$ : Nilai rata-rata posttest

$S D_{\text {pre }} \quad$ : Standar deviasi pretest

Setelah effect size dihitung, selanjutnya dikategorikan pada tingkatan sebagai berikut:

Tabel 1.Kriteria Effect Size (ES)

\begin{tabular}{ccc}
\hline No & ES & Kategori \\
\hline 1 & $\mathrm{ES} \leq 0,15$ & Dapat Diabaikan \\
\hline 2 & $0,15<\mathrm{ES} \leq 0,40$ & Rendah \\
\hline 3 & $0,40<\mathrm{ES} \leq 0,75$ & Sedang \\
\hline 4 & $0,75<\mathrm{ES} \leq 1,10$ & Tinggi \\
\hline 5 & $1,10<\mathrm{ES} \geq 1,45$ & Sangat Tingi \\
\hline
\end{tabular}

Adapun persamaan lain untuk mencari effect size adalah sebagai berikut:

a. Rata-rata dan standar deviasi two group posttest only

$$
\mathrm{ES}=\frac{\underline{x}_{E}-\underline{x}_{C}}{S D_{C}}
$$

Keterangan :

$$
\begin{aligned}
\mathrm{ES} & \text { Effect Size } \\
\underline{x}_{E}: & \text { Nilai rata-rata post test } \\
& \text { kelompok eksperimen }
\end{aligned}
$$


$\underline{x}_{C}$ : Nilai rata-rata post test kelompok kontrol

$S D_{C} \quad$ : Standar deviasi kontrol

b. Rata-rata dan standar deviasi two group pre-post test

$\mathrm{ES}=\frac{\left(\underline{x}_{\text {post }}-\underline{x}_{\text {pre }}\right)_{E}-\left(\underline{x}_{\text {post }}-\underline{x}_{\text {pre }}\right)_{C}}{\frac{S D_{\text {preC }}+S D_{\text {preE }}+S D_{\text {post } C}}{3}}$.

Keterangan :

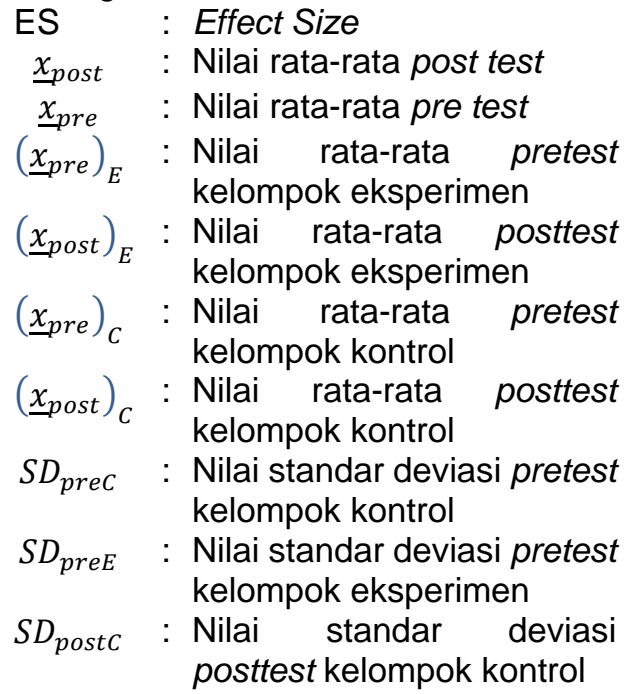

c. Jika standar deviasi tidak diketahui maka dapat dilakukan dengan uji t

$\mathrm{ES}=t \sqrt{\frac{1}{n_{E}}+\frac{1}{n_{C}}}$

Keterangan :

$\begin{array}{clll}\text { ES } & : \text { Effect Size } & \\ t & : \text { Hasil uji t } & \\ n_{E} & : \text { Jumlah sampel kelompok } \\ & \text { eksperimen } & \\ n_{C} & : \text { Jumlah sampel kelompok } \\ & \text { kontrol }\end{array}$

\section{HASIL DAN PEMBAHASAN}

\section{Hasil Penelitian}

Penelitian ini adalah penelitian meta analisis. Analisis menggunakan 17 artikel mulai dari tahun 2015 sampai 2021 yang terdiri dari jurnal nasional dan internasional terkait dengan pengaruh model discovery learning terhadap penguasaan konsep dan hasil belajar fisika peserta didik. Artikel-artikel dalam lima tahun terakhir yang telah dipilih untuk meta analisis ini diberi kode J1 sampai dengan J17. Variabel yang diukur adalah untuk mencari ukuran effect size pada setiap artikel.

Hasil pertama dalam penelitian meta analisis ini terkait pengaruh discovery learning terhadap penguasaan konsep dan pengetahuan fisika SMA ditinjau tahun terbit artikel. Nilai rata-rata ukuran efek ditinjau dari tahun terbit artikel didapatkan dari perhitungan ukuran efek dari masing-masing artikel. Nilai rata-rata ukuran efek ditinjau dari tahun terbit yang digunakan dari 17 artikel dapat dilihat pada Tabel 2.

Tabel 2. Nilai effect size Pengaruh model discovery learning terhadap penguasaan konsep dan pengetahuan fisika SMA berdasarkan Tahun Terbit artikel.

\begin{tabular}{|c|c|c|c|c|}
\hline $\begin{array}{l}\text { Kode } \\
\text { Jurnal }\end{array}$ & Tahun & $\begin{array}{c}\text { Effect } \\
\text { Size }\end{array}$ & $\begin{array}{l}\text { Rata- } \\
\text { rata } \\
\text { effect } \\
\text { size } \\
\text { berdas } \\
\text { arkan } \\
\text { tahun } \\
\text { terbit }\end{array}$ & Kategori \\
\hline J11 & 2015 & 0,73 & 0,73 & Sedang \\
\hline $\begin{array}{c}\mathrm{J} 2 \\
\mathrm{~J} 13\end{array}$ & 2016 & $\begin{array}{l}1,13 \\
0,54\end{array}$ & 0,84 & Tinggi \\
\hline $\begin{array}{l}\text { J6 } \\
\text { J9 }\end{array}$ & 2017 & $\begin{array}{l}2,38 \\
0,82\end{array}$ & 1,6 & $\begin{array}{c}\text { Sangat } \\
\text { Tinggi }\end{array}$ \\
\hline $\begin{array}{l}\mathrm{J} 14 \\
\mathrm{~J} 16\end{array}$ & 2018 & $\begin{array}{l}0,42 \\
1,87\end{array}$ & 1,15 & $\begin{array}{c}\text { Sangat } \\
\text { Tinggi }\end{array}$ \\
\hline $\begin{array}{c}\text { J4 } \\
\text { J7 } \\
\text { J8 } \\
\text { J15 } \\
\text { J17 }\end{array}$ & 2019 & $\begin{array}{l}0,98 \\
0,59 \\
0,69 \\
0,68 \\
0,47\end{array}$ & 0,68 & Sedang \\
\hline $\begin{array}{c}\mathrm{J} 1 \\
\mathrm{~J} 3 \\
\mathrm{~J} 10 \\
\mathrm{~J} 12\end{array}$ & 2020 & $\begin{array}{l}1,29 \\
0,74 \\
3,95 \\
0,49\end{array}$ & 1,62 & $\begin{array}{l}\text { Sangat } \\
\text { Tinggi }\end{array}$ \\
\hline J5 & 2021 & 0,89 & 0,89 & Tinggi \\
\hline
\end{tabular}

Berdasarkan data pada Tabel 2 dapat dijelaskan bahwa Pengaruh model discovery learning terhadap penguasaan konsep dan pengetahuan fisika SMA dari 17 artikel yang diperoleh berdasarkan tahun terbit artikel dapat diketahui ukuran effect size, yaitu artikel yang terbit pada tahun 2015 terdapat 1 artikel dengan rata-rata effect size 0,73; tahun 2016 terdapat 2 artikel dengan rata-rata effect size 0,84; tahun 2017 terdapat 2 artikel dengan rata-rata effect size 1,6 ; tahun 2018 terdapat 2 artikel dengan rata-rata effect size 1,15; tahun 2019 terdapat 5 artikel dengan rata-rata effect size 0,68; tahun 2020 terdapat 4 artikel dengan rata-rata effect size 1,62; dan tahun 2021 terdapat 1 artikel dengan rata-rata effect size 0,89. Dari Tabel 2 dapat dideskripsikan bahwa model discovery learning memberikan ukuran effect size yang Sangat Tinggi terhadap penguasaan konsep dan pengetahuan fisika SMA berdasarkan tahun terbit artikel adalah pada tahun 2017,2018, dan 2020. Hal ini menunjukkan bahwa terdapat pengaruh penggunaan model discovery learning terhadap penguasaan 
konsep dan pengetahuan fisika SMA berdasarkan tahun terbit artikel.

Hasil kedua dalam penelitian meta analisis ini terkait pengaruh discovery learning terhadap penguasaan konsep dan pengetahuan fisika SMA ditinjau dari tingkatan kelas. Nilai rata-rata ukuran efek ditinjau dari tingkatan kelas didapatkan dari perhitungan ukuran efek dari masing-masing artikel. Nilai rata-rata ukuran efek ditinjau dari tingkatan kelas yang digunakan dari 17 artikel dapat dilihat pada Tabel 3.

Tabel 3. Nilai effect size Pengaruh model discovery learning terhadap penguasaan konsep dan pengetahuan fisika SMA berdasarkan Tingkatan Kelas

\begin{tabular}{|c|c|c|c|c|}
\hline $\begin{array}{l}\text { Kode } \\
\text { Jurnal }\end{array}$ & Kelas & $\begin{array}{c}\text { Effect } \\
\text { Size }\end{array}$ & $\begin{array}{l}\text { Rata- } \\
\text { rata } \\
\text { effect } \\
\text { size }\end{array}$ & Kategori \\
\hline J2 & \multirow{10}{*}{$x$} & 1,13 & \multirow{10}{*}{0,99} & \multirow{10}{*}{ Tinggi } \\
\hline J5 & & 0,89 & & \\
\hline J6 & & 2,38 & & \\
\hline J7 & & 0,59 & & \\
\hline J9 & & 0,82 & & \\
\hline J11 & & 0,73 & & \\
\hline J12 & & 0,49 & & \\
\hline J13 & & 0,54 & & \\
\hline J16 & & 1,87 & & \\
\hline J17 & & 0,47 & & \\
\hline J1 & \multirow{7}{*}{ XI } & 1,29 & \multirow{7}{*}{1,25} & \multirow{7}{*}{$\begin{array}{l}\text { Sangat } \\
\text { Tinggi }\end{array}$} \\
\hline J3 & & 0,74 & & \\
\hline J4 & & 0,98 & & \\
\hline J8 & & 0,69 & & \\
\hline J10 & & 3,95 & & \\
\hline J14 & & 0,42 & & \\
\hline J15 & & 0,68 & & \\
\hline
\end{tabular}

Berdasarkan data pada Tabel 3 dapat dijelaskan bahwa Pengaruh model discovery learning terhadap penguasaan konsep dan pengetahuan fisika SMA dari 17 artikel yang diperoleh berdasarkan tingkatan kelas dapat diketahui ukuran effect size, yaitu pada tahun kelas $X$ terdapat 10 artikel dengan rata-rata effect size 0,99 dengan kategori Tinggi dan kelas XI terdapat 7 artikel dengan rata-rata effect size 1,25 dengan kategori Sangat Tinggi. Dari Tabel 3 dapat dideskripsikan bahwa model discovery learning memberikan ukuran effect size yang Sangat Tinggi terhadap penguasaan konsep dan Hasil Belajar fisika peserta didik berdasarkan tingkatan kelas adalah pada kelas XI dengan kategori Sangat Tinggi. Hal ini menunjukkan bahwa terdapat pengaruh penggunaan model discovery learning terhadap penguasaan konsep dan pengetahuan fisika SMA berdasarkan tingkatan kelas.
Hasil ketiga dalam penelitian meta analisis ini terkait pengaruh discovery learning terhadap penguasaan konsep fisika SMA. Nilai rata-rata ukuran efek ditinjau dari penguasaan konsep fisika peserta didik didapatkan dari perhitungan ukuran efek dari masing-masing artikel. Nilai rata-rata ukuran efek ditinjau dari penguasaan konsep fisika peserta didik terdapat 10 artikel dapat dilihat pada Gambar 1.

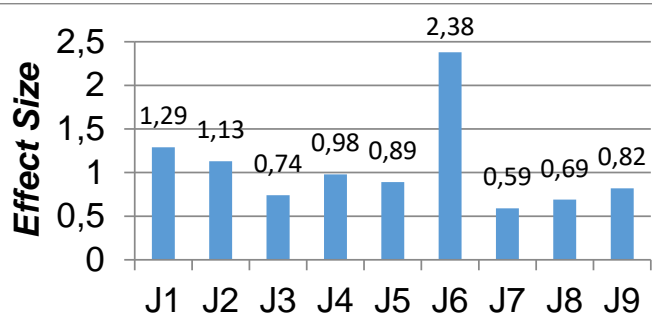

Artikel Ke-

Gambar 1. Nilai effect size Pengaruh model discovery learning terhadap penguasaan konsep fisika

Dari data pada Gambar 1 dapat dinyatakan bahwa ukuran effect size model discovery learning terhadap penguasaan konsep fisika terdapat 9 artikel. Pada artikel tersebut ukuran effect size terendah didapatkan pada artikel ketujuh (J7) dengan nilai effect size 0,59 . Sedangkan ukuran effect size tertinggi didapatkan pada artikel keenam (J6) dengan nilai effect size 2,38. Masing-masing artikel memberikan efek yang positif. Hal ini menunjukan bahwa terdapat pengaruh model discovery learning terhadap penguasaan konsep fisika.

Hasil keempat dalam penelitian meta analisis ini terkait pengaruh discovery learning terhadap pengetahuan fisika SMA. Nilai ratarata ukuran efek ditinjau dari pengetahuan fisika SMA didapatkan dari perhitungan ukuran efek dari masing-masing artikel. Nilai rata-rata ukuran efek ditinjau dari pengetahuan fisika SMA terdapat 8 artikel dapat dilihat pada Gambar 2. 


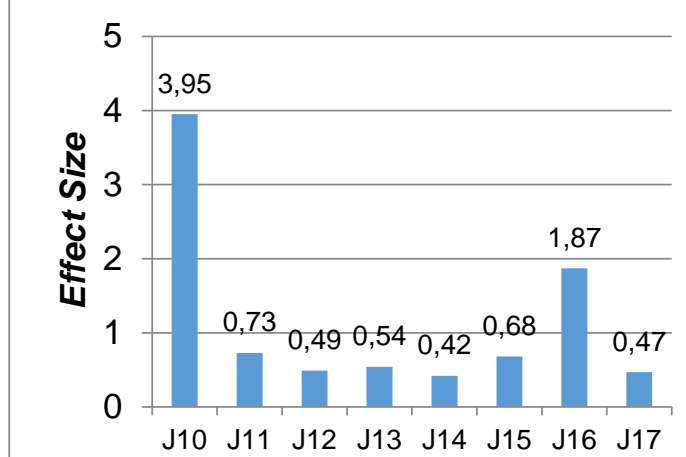

Artikel Ke-

Gambar 2. Nilai effect size Pengaruh model discovery learning terhadap pengetahuan peserta didik fisika SMA

Dari data pada Gambar 2 dapat dinyatakan bahwa ukuran effect size model discovery learning terhadap pengetahuan fisika terdapat 8 artikel. Pada artikel tersebut ukuran effect size terendah didapatkan pada artikel keempat belas (J14) dengan nilai effect size 0,42 . Sedangkan ukuran effect size tertinggi didapatkan pada artikel kesepuluh (J10) dengan nilai effect size 3,95. Masing-masing artikel memberikan efek yang positif. Hal ini menunjukan bahwa terdapat pengaruh model discovery learning terhadap pengetahuan fisika SMA.

\section{Pembahasan}

Penelitian ini bertujuan untuk melihat hasil penelitian terkait dengan pengaruh model discovery learning terhadap penguasaan konsep dan pengetahuan fisika SMA. Penelitian ini menghitung nilai effect size hubungan antar variabel dengan variabel lainnya.

Hasil penelitian ini dilakukan pada kategori effect size pengaruh model discovery learning terhadap penguasaan konsep dan pengetahuan fisika SMA. Hasil penelitian pertama meta analisis ini terkait pengaruh model discovery learning terhadap penguasaan konsep dan pengetahuan fisika SMA ditinjau dari tahun terbit artikel memberikan efek yang Sangat Tinggi terdapat pada tahun 2017, 2018, dan 2020. Hasil penelitian kedua meta analisis ini terkait pengaruh model discovery learning terhadap penguasaan konsep dan pengetahuan fisika SMA ditinjau dari tingkatan kelas memberikan efek Sangat Tinggi terdapat pada kelas XI. Hasil penelitian ketiga meta analisis ini terkait pengaruh discovery learning terhadap penguasaan konsep fisika SMA memberikan efek Sangat Tinggi terdapat pada artikel keenam (J6). Hasil penelitian keempat meta analisis ini terkait pengaruh discovery learning terhadap pengetahuan fisika SMA memberikan efek Sangat Tinggi terdapat pada artikel kesepuluh (J10). Hal ini menunjukkan bahwa pengaruh model discovery learning terhadap penguasaan konsep dan pengetahuan fisika SMA meningkat.

\section{SIMPULAN DAN SARAN}

Berdasarkan meta analisis yang dilakukan dapat dinyatakan bahwa hasil dari penelitian ini, yaitu pengaruh model discovery learning terhadap penguasaan konsep dan pengetahuan fisika SMA meningkat. Hasil penelitian pertama meta analisis ini terkait pengaruh model discovery learning terhadap penguasaan konsep dan pengetahuan fisika SMA ditinjau dari tahun terbit artikel memberikan efek yang Sangat Tinggi terdapat pada tahun 2017, 2018, dan 2020 dengan masing-masing rata-rata effect size yaitu 1,6; 1,15; dan 1,62. Hasil penelitian kedua meta analisis ini terkait pengaruh model discovery learning terhadap penguasaan konsep dan pengetahuan fisika SMA ditinjau dari tingkatan kelas memberikan efek Sangat Tinggi terdapat pada kelas XI dengan rata-rata effect size 1,25. Hasil penelitian ketiga meta analisis ini terkait pengaruh discovery learning terhadap penguasaan konsep fisika SMA memberikan efek Sangat Tinggi terdapat pada artikel keenam (J6) dengan nilai effect size 2,38. Hasil penelitian keempat meta analisis ini terkait pengaruh discovery learning terhadap pengetahuan fisika SMA memberikan efek Sangat Tinggi terdapat pada artikel kesepuluh (J10) dengan nilai effect size 3,95. Hal ini menunjukkan bahwa terdapat pengaruh model discovery learning terhadap penguasaan konsep dan pengetahuan fisika SMA .

\section{UCAPAN TERIMAKASIH}

Terima kasih penulis sampaikan yang sebesar-besarnya kepada Bapak Dr. Asrizal, M.Si., dan Ibu Dr. Fatni Mufit, M.Si., selaku dosen pengampu mata kuliah pengembangan model pembelajaran fisika yang selalu sabar dan ikhlas dalam mengajar serta memberikan saran dan masukan hingga penulisan artikel ini selesai.

\section{DAFTAR RUJUKAN}

Adlina, Manurung, S. R., \& Apriani, Y. (2019). Efektivitas model discovery learning berbantuan simulasi phet terhadap hasil belajar fisika di kelas X sma swasta alwashliyah 1 medan. Jurnal Inovasi Pembelajaran Fisika (INPAFI), 7(4), 9-16. http://jurnal.unimed.ac.id/2012/index.php/ inpafi

Andi, H. J. (2017). SISWA SMA DENGAN MENGGUNAKAN MODEL DISCOVERY 
LEARNING. 99-104.

Asrizal, A., Amran, A., Ananda, A., \& Festiyed, F. (2019). Effects of instructional material of natural science with literacy skills of our respiratory and excretory health theme on academic achievement of students. Journal of Physics: Conference Series, 1317(1),

https://doi.org/10.1088/1742-

6596/1317/1/012174

Destalina, D., Ali, M. S., \& Palloan, P. (2019). Efektivitas Penerapan Discovery Learning Pada Pembelajaran Sains Berorientasi Inquiry Terhadap Pemahaman Konsep Fisika Peserta Didik Kelas Xi Ipa Sma Negeri 13 Makassar. Jurnal Sains Dan Pendidikan Fisika, 15(1), 1-7. https://doi.org/10.35580/jspf.v15i1.9405

Faradhillah, F., Marhami, M., \& Hadiya, I. (2021). Application of Discovery Learning Models To Improve Conceptual Mastery of Newton Force And Law. IJIS Edu: Indonesian Journal of Integrated Science Education, 3(1), 2021-2069. https://ejournal.iainbengkulu.ac.id/index.p $\mathrm{hp} / \mathrm{ijisedu/article/view/4174}$

Farid, A. M. M., Faradiyah, A. R., Maghfira, A., Lestari, A. P., \& Tullah, H. (2018). Pengaruh Media Simulasi Phet Menggunakan Model Discovery Learning Terhadap Hasil Belajar Fisika Peserta Didik the Influence of Phet ( Physics Education Technology ) Simulation Media on Physics Subjects Using Discovery. Jurnal Nalar Pendidikan, 6(2), 105-112.

Hal, N., Rawanti, R., Werdhiana, I. K., \& Pasaribu, M. (2020). Pengaruh Model Discovery Learning dengan Multirepresentasi terhadap Hasil Belajar Fisika Siswa pada Materi Gerak Lurus. Musamus Journal of Science Education, 3(1). ( Suryosubroto ,. 3, 31-39. https://doi.org/10.3572/mjose.v3i1.3578

Kadri, M., \& Rahmawati, M. (2015). Pengaruh Model Pembelajaran Discovery Learning Terhadap Hasil Belajar Siswa Pada Materi Pokok Suhu Dan Kalor. Jurnal Ikatan Alumni Fisika, 1(1), 21. https://doi.org/10.24114/jiaf.v1i1.2692

Liang Tao, Y. A. N., \& Xiaoli, X. (2019). 严良涛 1 (1 (2 项晓丽 2. 38(3), 3-6.

Mufit, F., Asrizal, A., \& Puspitasari, R. (2020). Meta-Analysis of the Effect of Cognitive Conflict on Physics Learning. Jurnal Penelitian \& Pengembangan Pendidikan Fisika, 6(2), 267-278. https://doi.org/10.21009/1.06213

Nurulhidayah, M. R., Lubis, P. H. M., \& Ali, M. (2020). PENGARUH MODEL
PEMBELAJARAN

DISCOVERY

LEARNING MENGGUNAKAN MEDIA

SIMULASI PhET TERHADAP

PEMAHAMAN KONSEP FISIKA SISWA.

Jurnal Pendidikan Fisika, 8(1), 95. https://doi.org/10.24127/jpf.v8i1.2461

Pulsation, H., \& Technology, F. (2015). 液压脉

动滤波技术研究陈耿彪 1，贺尚红22.

4(12),

$10-14$.

https://doi.org/10.3969/j.issn.1008-

0813.2015.03.002

Rosarina, G., Sudin, A., \& Sujana, A. (2016). Penerapan Model Discovery Learning Untuk Meningkatkan Hasil Belajar Siswa Pada Materi Perubahan Wujud Benda. Jurnal Pena IImiah, 1(1), 371-380. https://doi.org/10.17509/jpi.v1i1.3043

Rosmiati, R., Hikmawati, H., \& Harjono, A. (2020). Pengaruh Model Discovery Learning Terhadap Penguasaan Konsep Fisika Peserta Didik Kelas Xi Man 1 Lombok Barat. Jurnal IImiah Profesi Pendidikan, 5(1), 29-34. https://doi.org/10.29303/jipp.v5i1.100

Rudibyani, R. B. (2019). Peningkatan Keterampilan Berpikir Elaborasi dan Penguasaan Konsep Elektrolisis Siswa Melalui Discovery Learning. Jurnal Sains Dan Edukasi Sains, 2(2), 60-69. https://doi.org/10.24246/juses.v2i2p60-69

Sains, C., \& Fisika, J. P. (2020). EFEKTIVITAS MODEL DISCOVERY LEARNING BERBANTUAN PhET. 1, 108-112.

Sari, D. P., \& Simanjuntak, M. P. (2016). Pengaruh Model Discovery Learning Berbantuan Media Phet Terhadap Hasil Belajar Siswa. INPAFI (Inovasi Pembelajaran Fisika), 4(4). https://doi.org/10.24114/inpafi.v4i4.5631

Sari, P. I., Gunawan, G., \& Harjono, A. (2017). Penggunaan Discovery Learning Berbantuan Laboratorium Virtual pada Penguasaan Konsep Fisika Siswa. Jurnal Pendidikan Fisika Dan Teknologi, 2(4), 176. https://doi.org/10.29303/jpft.v2i4.310

Silaban, B. (2014). Hubungan antara penguasaan konsep fisika dan kreativitas dengan kemampuan memecahkan masalah pada materi pokok listrik statis. Jurnal Penelitian Bidang Pendidikan, 20(1), 65-75.

Simatupang, J. M., \& Simamora, P. (2019). Pengaruh Model Pembelajaran Discovery Learning Terhadap Hasil Belajar Siswa Pada Materi Pokok Momentum, Impuls Dan Tumbukan Kelas X Semester li Di Sma N 1 Pancurbatu Tp. 2016/2017. INPAFI (Inovasi Pembelajaran Fisika), 6(4). 
https://doi.org/10.24114/inpafi.v6i4.12482 Suranti, N. M. Y., Gunawan, G., \& Sahidu, H. (2017). Pengaruh Model Project Based Learning Berbantuan Media Virtual Terhadap Penguasaan Konsep Peserta didik pada Materi Alat-alat Optik. Jurnal Pendidikan Fisika Dan Teknologi, 2(2), 73. https://doi.org/10.29303/jpft.v2i2.292 